\title{
Coexpression of CAV-1, AT1-R and FOXM1 in prostate and breast cancer and normal cell lines and their influence on metastatic properties
}

\author{
Karolina Kowalska ${ }^{1 *}$, Magdalena Nowakowska2* , Kamila Domińska ${ }^{1}$ and \\ Agnieszka W. Piastowska-Ciesielska1 ${ }^{\varpi}$
}

1Department of Comparative Endocrinology and 2Department of Molecular Cancerogenesis, Faculty of Biomedical Sciences and Postgraduate Training, Medical University of Lodz, Łódź, Poland

The aim of this study was to evaluate the coexpression of caveolin-1 (CAV-1), angiotensin II type 1 receptor (AT1-R) and forkhead box MI (FOXM1) in prostate and breast cancer cell lines, in comparison with normal cell lines. CAV-1, AT1-R and FOXM1 expression was determined by reverse transcription-quantitative polymerase chain reaction and western blot analysis in the prostate cancer cell lines PC3, DU145 and LNCaP; prostate normal cell line PNT1A; breast cancer cell lines MCF-7 and MDAMB-231; and the normal breast cell line 184A1. A correlation between the expression levels of the investigated genes and their metastatic properties was determined by the Spearman's rank test $(P<0.05)$ and Aspin-Welsch $t$-test, respectively. In prostate cell lines, a significant correlation was noted between CAV-1 and AT1-R expression and between FOXM1 and CAV-1 expression. A correlation between the expression levels of the investigated genes and their metastatic potential was also observed, with relatively high expression of all the investigated genes in the normal prostate cell line PNT1A. In comparison to prostate cancer cell lines, an adverse dependency between CAV-1, AT1-R, FOXM1 expression and metastatic potential was observed in the breast cancer cell lines. Relatively high expression of all tested genes was observed in the normal breast cell line 184A1, which was decreasing respectively with increasing metastatic potential of breast cancer cell lines. The results obtained here indicate that CAV-1, FOXM1 and AT1-R may be potential markers of tumorigenesis in certain types of cancer in vitro.

Key words: angiotensin II receptor type 1; caveolin-1; breast adenocarcinoma; forkhead M1 transcription factor; prostate adenocarcinoma

Received: 24 March, 2015; revised: 08 April, 2016; accepted: 12 May, 2016; available on-line: 20 May, 2016

\section{INTRODUCTION}

The process of cancerogenesis is a multistep process that comprises various complex changes at the genomic, transcriptomic and proteomic levels (Mahmoud et al., 2015). The last event of this process is metastasis, which leads to cancer cell dissemination and development of novel tumours at different sites. The leading cancer types in epidemiological statistics are those associated with the reproductive tract, particularly breast and prostate cancer. It is of interest to elucidate the molecular mechanisms responsible for the development and progression of these tumours and to identify novel molecular markers that enable early diagnosis and characterization of tumour features (Siegel et al., 2015).

The expression of caveolin-1 (CAV-1) and angiotensin II (Ang II) appears to be associated with cancer progression and metastatic potential (Piastowska-Ciesielska et al., 2013a). CAV-1 is a $22 \mathrm{kDa}$ hairpin membrane protein that forms part of a caveolae, the non-clathrin subdomains of lipid rafts (Goetz et al., 2008; Yang et al., 2012). CAV-1 is known to participate in cell signalling, cellular transformation, metastasis, cell death, survival and angiogenesis via interactions with growth factor receptors, cytokines, oncoproteins and metalloproteinases (Bouras et al., 2004; Burgermeister et al., 2008; Han \& Zhu, 2010; Trimmer et al., 2011). The expression levels of CAV-1 may vary depending on the type and stage of the tumour. For example, high levels of CAV-1 have been reported in metastatic prostate cancer (Piastowska-Ciesielska et al., 2013a), while in breast cancer CAV-1 has been reported to act as a tumour suppressor, regulating the expression of breast cancer 1, early onset (BRCA1), epidermal growth factor receptor (EGFR), the E3 ubiquitin-protein ligase mouse double minute 2 homolog (Mdm2) and the oncoprotein signal transducer and activator of transcription 3 (Stat3) (Glait et al., 2006; Agelaki et al., 2009; Bartholomew et al., 2009; Chiu et al., 2011).

Ang II is the major element of the renin-angiotensin system, which is involved in oxidative stress, maintenance of the water balance in the body and development of hypertension (Uemura et al., 2008a; Jethon et al., 2012). It is well documented that Ang II has a potential role in carcinogenesis by activating the mitogen-activated protein kinases (MAPKs) (Uemura et al., 2008a), growth factors (Uemura et al., 2005b) and angiogenesis (Uemura et al., 2005a). Thus, overexpression of Ang II type 1 re-

e-mail: agnieszka.piastowska@umed.lodz.pl

*These authors contributed equally

Abbreviations: Ang II, angiotensin II; AT1-R, angiotensin II type 1 receptor; ATCC, American Type Culture Collection; BRCA1, breast cancer, early onset 1; CAV-1, caveolin-1; ECACC, European Collection of Authenticated Cell Cultures; EGFR, epidermal growth factor receptor; FOXM1, forkhead box $M 1$; GAPDH, glyceraldehydes 3-phosphate dehydrogenase; H3F3A, H3 histone, family $3 \mathrm{~A}_{\text {; }}$ HEPES, 4-(2-hydroxyethyl)-1-piperazineethanesulfonic acid buffer; MAPKs, mitogen-activated protein kinases; Mdm2, E3 ubiquitinprotein ligase mouse double minute 2 homolog; MMP2, matrix metalloproteinase 2; MMP9, matrix metalloproteinase 9; mRNA, messenger RNA; RIPA, radioimmunoprecipitation assay extraction buffer: RPS17, ribosomal protein 17; RT-qPCR, reverse transcription-quantitative polymerase chain reaction; Stat3, signal transducer and activator of transcription; TE, Tris-ethylenediaminetetraacetic acid; VEGF, vascular endothelial growth factor 
ceptor (AT1-R) has been described to correlate with invasiveness of prostate, breast and ovarian cancers (Dominska \& Lachowicz-Ochedalska, 2008).

Forkhead box M1 (FOXM1) is a transcription factor that is overexpressed during development (Laoukili et al., 2007). In adult tissues, its expression is suppressed in resting or terminally differentiated cells, with the exception of actively dividing cells in the testis and thymus (Glait et al., 2006; Laoukili et al., 2007; Kalin et al., 2011). Furthermore, increased expression of FOXM1 and amplification of its gene region have been associated with various types of human cancer, including glioblastoma (Liu et al., 2006), non-small cell lung cancer (Kim et al., 2006), prostate adenocarcinoma (Kalin et al., 2006) and breast cancer (Millour et al., 2010). In addition, it has been shown that this member of the forkhead family of transcription factors also participates in the regulation of cancer-associated processes, including invasion, angiogenesis and metastasis (Chandran et al., 2007; Wang et al., 2008; Park et al., 2011; Bergamaschi et al., 2014), through direct transcriptional regulation of vascular endothelial growth factor (VEGF) (Zhang et al., 2008), matrix metalloproteinase 2 (MMP2), MMP9 (Dai et al., 2007; Wang et al., 2008) and CAV-1 (Huang et al., 2012). A strong correlation between FOXM1 and CAV-1 expression has been demonstrated in pancreatic cancer, indicating that these proteins are associated with cancer development and progression (Huang et al., 2012). As previously reported, CAV-1 may modulate the expression of AT1-R by controlling its transport to the plasma membrane in prostate cells as a part of lipid rafts (Piastowska-Ciesielska et al., 2013a). Since FOXM1 and CAV-1 expression are correlated, FOXM1 may also participate in the regulation of cancerogenesis of prostate and breast cells. Thus, the study presented here aimed to compare the expression of AT1-R, CAV-1 and FOXM1 in prostate and breast cancer cell lines, which exhibit a different metastatic potential to that of normal prostate and breast cell lines, in order to identify any significant pattern of their coexpression and participation in the acquisition of cancer progression features. To the best of our knowledge, this study is the first report on differences in the expression levels of AT1-R in cancer cell lines exhibiting distinct metastatic properties.

\section{MATERIALS AND METHODS}

Cell culture. Metastatic human prostate adenocarcinoma cell lines LNCaP and PC3 were obtained from the German Collection of Microorganisms and Cell Cultures $\mathrm{GmbH}$ (Brunswick, Germany), whereas the DU145 cells and normal adult prostatic epithelial PNT1A cells were obtained from the American Type Culture Collection (ATCC; Manassas, VA, USA) and the European Collection of Authenticated Cell Cultures (ECACC; Salisbury, UK), respectively. Mammary gland adenocarcinoma cell lines MCF-7 and MDAMB-231, and normal mammary gland 184A1 cells were obtained from ATCC. Cell lines were cultured in RPMI or Dulbecco's modified Eagle's medium with $10 \%$ heat-inactivated foetal bovine serum, $2 \mathrm{mM}$ L-glutamine, $1 \mathrm{mM}$ sodium pyruvate, $10 \mathrm{mM}$ 4-(2-hydroxyethyl)-1-piperazineethanesulfonic acid buffer (HEPES) and antibiotics (penicillin, $50 \mathrm{U} / \mathrm{ml}$; streptomycin, $50 \mu \mathrm{g} / \mathrm{ml}$; and neomycin, $100 \mu \mathrm{g} / \mathrm{ml}$ ), in a humidified atmosphere of $5 \% \mathrm{CO}_{2}$ at $37^{\circ} \mathrm{C}$. Cells were cultured in 6-well culture dishes for RNA and protein isolation. All cell culture media, reagents and cell dish- es were obtained from Thermo Fisher Scientific, Inc. (Waltham, MA, USA).

Isolation of protein and RNA. Total protein extracts were isolated using a radioimmunoprecipitation assay extraction buffer (RIPA; Sigma-Aldrich, St. Louis, MO, USA), supplemented with protease and phosphatase inhibitor cocktails (Sigma-Aldrich) and $1 \mathrm{mM}$ phenylmethylsulfonyl fluoride (Sigma-Aldrich). Protein concentration was determined by the Bradford method using a commercially available kit (Bio-Rad Laboratories, Inc., Hercules, CA, USA), as previously described (Piastowska-Ciesielska et al., 2011).

For RNA isolation, cells were suspended in the TRIzol reagent (Life Technologies; Thermo Fisher Scientific, Inc.), and processed according to the manufacturer's protocol. Isolated RNA was diluted in $50 \mu \mathrm{l}$ of sterile deionised water. The RNA concentration was determined spectrophotometrically with Spectometer Lambda 25 UV/VIS (PerkinElmer, Waltham, MA, USA) in Tris-ethylenediaminetetraacetic acid (TE) buffer at 260 and $280 \mathrm{~nm}$.

Western blot analysis. Protein samples were mixed with the Laemmli sample buffer (Sigma-Aldrich) and heated at $100^{\circ} \mathrm{C}$ for $3 \mathrm{~min}$. Total of $60 \mu \mathrm{g}$ of protein for FOXM1, and $30 \mu \mathrm{g}$ of protein for CAV-1 and AT1-R, were separated electrophoretically on $12.5 \%$ sodium dodecyl sulphate-polyacrylamide gels (Bio-Rad Laboratories, Inc.), and then transferred to polyvinylidene fluoride membranes (Sigma-Aldrich) by semi-dry blotting (Whatman, Biometra GmbH, Göttingen, Germany). Membranes were visualized prior to blocking with a Ponceau $\mathrm{S}$ dye $0.1 \%$ solution in $5 \% \mathrm{CH}_{3} \mathrm{COOH}$ (Sigma-Aldrich). Subsequently, the membranes were blocked in $5 \%$ fatfree milk (Sigma-Aldrich) for $1 \mathrm{~h}$ prior to overnight incubation at $4^{\circ} \mathrm{C}$ with primary rabbit anti-CAV-1 polyclonal antibody (dilution 1:200; catalogue no. SC-894 Santa Cruz Biotechnology, Inc., Dallas, TX, USA), rabbit anti-FOXM1 polyclonal antibody (dilution 1:500, catalogue no. ABN286; Merck Millipore, Darmstadt, Germany) and rabbit anti-AT1-R polyclonal antibody (dilution 1:200; catalogue no. SC-1173; Santa Cruz Biotechnology, Inc.), which were diluted in $1 \%$ fat-free milk. As a reference, mouse anti-glyceraldehyde 3-phosphate dehydrogenase monoclonal antibody (GAPDH; dilution 1:1000; catalogue no. SC-59540; Santa Cruz Biotechnology, Inc.) was used. Next, membranes were washed three times for $15 \mathrm{~min}$ with Tris-buffered saline-Tween 20 (TBST) buffer, and incubated for $1 \mathrm{~h}$ with secondary antibodies conjugated with alkaline phosphatase: anti-rabbit IgG (catalogue no. A3687), anti-mouse IgG (catalogue no. A3562) (dilutions 1:15000; Sigma-Aldrich). Following three washes in TBST buffer for $15 \mathrm{~min}$, the bands were visualized using Novex ${ }^{\circledR}$ AP Chromogenic Substrate (BCIP/NBT) (Life Technologies; Thermo Fisher Scientific, Inc.). Densitometric analysis of protein expression levels was conducted as previously described, using ImageJ version 1.34 software (http://rsb. info.nih.gov/ij/; National Institutes of Health, Bethesda, MD, USA) (Piastowska-Ciesielska et al., 2014). The results of western blot analysis were calculated as the ratio of CAV-1, FOXM1 and AT1-R expression, compared to the GAPDH expression.

Reverse transcription-quantitative polymerase chain reaction (RT-qPCR). Complementary DNA was transcribed from $5 \mu \mathrm{g}$ of total RNA using ImProm RT-IITM Reverse Transcription System (Promega Corporation, Madison, WI, USA), according to the manufacturer's protocol. RT was conducted in a LightCy$\operatorname{cler}^{\circledR} 480$ instrument (Roche Diagnostics, Basel, Swit- 
Table 1. Sequences of primers used in this study.

\begin{tabular}{|c|c|c|}
\hline Gene & Sequence of primers: & Product size [bp] \\
\hline AT1-R & $\begin{array}{l}\text { sense primer: 5'ATTCGACCCAGGTGATCAAA3' } \\
\text { antisense primer: 5'CCACCAAGCTGTITCCAAAT3' }\end{array}$ & 168 \\
\hline CAV-1 & $\begin{array}{l}\text { sense primer:5'AGTGCATCAGCCGTGTCTATTCCA3' } \\
\text { antisense primer: 5'TCTGCAAGTTGATGCGGACATTGC3' }\end{array}$ & 102 \\
\hline FOXM1 & $\begin{array}{l}\text { sense primer: } 5^{\prime} \text { TGCCCAGCAGTCTCTTACCT 3' } \\
\text { antisense primer: } 5^{\prime} \text { CTACCCACCTTCTGGCAGTC } 3^{\prime}\end{array}$ & 139 \\
\hline $\mathrm{H} 3 \mathrm{~F} 3 \mathrm{~A}$ & $\begin{array}{l}\text { sense primer: 5'AGGACTTAAAAGATCTGCGCTTCCAGAG3' } \\
\text { antisense primer: 5'ACCAGATAGGCCTCACTTGCCTCCTGC3' }\end{array}$ & 76 \\
\hline RPS17 & $\begin{array}{l}\text { sense primer: 5'AAGCGCGTGTGCGAGGAGATCG3' } \\
\text { antisense primer: 5'TCGCTTCATCAGATGCGTGACATAACCTG3' }\end{array}$ & 87 \\
\hline
\end{tabular}

AT1-R, angiotensin II type 1 receptor; CAV-1, caveolin-1; FOXM1, forkhead box M1; H3F3A, H3 histone, family 3A; RPS17, ribosomal protein S17

zerland), as previously described (Piastowska-Ciesielska et al., 2013b). Primers were designed using Primer3 106 version 0.4.0 software (http://frodo.wi.mit.edu/). qPCR was performed using a LightCycler ${ }^{\circledR}$ FastStartDNA Master 108 SYBR Green I kit (Roche Diagnostics), according to the manufacturer's protocol. Universal Human reference RNA (Stratagene; Agilent Technologies, Inc., Santa Clara, CA, USA) was used as a calibrator for each reaction. The relative expression of CAV-1, FOXM1 and AT1-R was normalized to the expression of the reference genes: ribosomal protein S17 (RPS17) and $\mathrm{H} 3$ histone, family $3 \mathrm{~A}(\mathrm{H} 3 \mathrm{~F} 3 \mathrm{~A})$. The sequences of the primer pairs used are listed in Table 1. In order to avoid detection of non-specific products, melting curve analysis was performed for each reaction, and the qPCR data were analysed according to the Roche algorithm (Pfaffl et al., 2002). Samples were evaluated from $\geq 4$ replicates.

Statistical analysis. Data were expressed as the mean \pm standard error. Statistical differences between the samples were analysed according to their metastatic potential using the Aspin-Welsch $t$-test. $P$-values were calculated using GraphPad Prism 5 software (GraphPad Software, Inc., La Jolla, CA, USA). $P<0.05$ was considered to indicate a statistically significant difference. Correlations between all the investigated genes were calculated by the Spearman's rank test $(P<0.05)$.

\section{RESULTS}

\section{CAV-1, FOXM1 and AT1-R expression in prostate cancer cell lines}

In prostate cell lines, a strong and significant correlation was noted between the messenger (m)RNA expression levels of CAV-1 and AT1-R [Spearman correlation coefficient $(\mathrm{rs})=0.6290 ; P=0.0067]$, and between the mRNA expression levels of FOXM1 and CAV-1 (rs=0.6719; $P=0.0016$ ). The correlation between AT1-R and FOXM1 was also positive, but not significant ( $\mathrm{rs}=0.3143 ; P>0.05$ ). The mean mRNA expression levels of the investigated genes and their statistical association with metastatic properties are presented in Tables 2 and 3, respectively.

A correlation between the expression levels of the investigated genes and their metastatic potential was noticed, with a relatively high expression of all the genes tested in the normal prostate cell line PNT1A. When considering only cancer cell lines, the lowest expression levels of all the investigated genes was observed for the LNCaP cell line, which also had the
Table 2. Mean expression levels of CAV-1, AT1-R and FOXM1 obtained by reverse transcription-quantitative polymerase chain reaction.

Metastatic potential was determined based on the well-documented properties of these genes, geometrical mean of H3F3A and RPS17 were used as control.

\begin{tabular}{lllll}
\hline & \multicolumn{4}{c}{ Mean expression level } \\
\hline Cell line & $\begin{array}{l}\text { Metastasis } \\
\text { potential }\end{array}$ & AT1-R & CAV-1 & FOXM1 \\
\hline PNT1A & 0 & 9.49 & 4.28 & 6.80 \\
\hdashline PC3 & medium & 30.00 & 3.60 & 8.06 \\
\hdashline DU-145 & high & 29.89 & 24.45 & 6.50 \\
\hline LNCaP & low & 3.25 & 0.05 & 0.69
\end{tabular}

CAV-1, caveolin-1; AT1-R, angiotensin II type 1 receptor; FOXM1, forkhead box M1.

Table 3. Statistical significance of the expression levels of various genes in respect to their metastatic potential, as obtained by reverse transcription-quantitative polymerase chain reaction analysis in prostate normal and cancer cell lines.

\begin{tabular}{llll}
\hline \multirow{2}{*}{ Metastasis potential } & \multicolumn{2}{l}{ P-value } \\
\cline { 2 - 4 } & CAV-1 & AT1-R & FOXM1 \\
\hline O vs. low & 0.004 & $\mathrm{~ns}$ & 0.005 \\
\hline 0 vs. high & 0.007 & 0.027 & $\mathrm{~ns}$ \\
\hline Low vs. high & 0.0035 & 0.01 & 0.031 \\
\hline Medium vs. low & $\mathrm{ns}$ & $\mathrm{ns}$ & 0.019 \\
\hline Medium vs. 0 & $\mathrm{~ns}$ & $\mathrm{~ns}$ & $\mathrm{~ns}$ \\
\hline Medium vs. high & 0.0058 & $\mathrm{~ns}$ & $\mathrm{~ns}$ \\
\hline
\end{tabular}

ns, not significant; CAV-1, caveolin-1; AT1-R, angiotensin II type 1 receptor; FOXM1, forkhead box M1.

lowest invasiveness capacity. CAV-1 expression was the highest in the DU145 cell line, while the expression of AT1-R and FOXM1 was comparable between PC3 and DU145 cells.

The protein expression profile of AT1-R suggests the influence of post-transcriptional mechanisms, resulting in relatively high protein expression levels in the LNCaP cell line $(P<0.01)$. The remaining cell lines expressed comparable levels of AT1-R, which were in general consistent with its mRNA expression profile. Significant differences were observed between the DU145 and LNCaP cell lines $(P<0.01)$ (Fig. 1A). CAV-1 protein expression was the highest in DU145 cells, while it was the lowest 
A

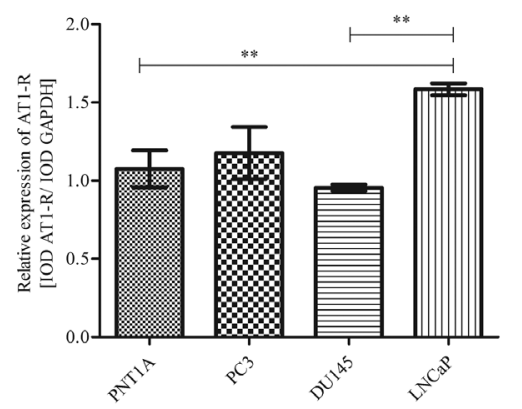

C

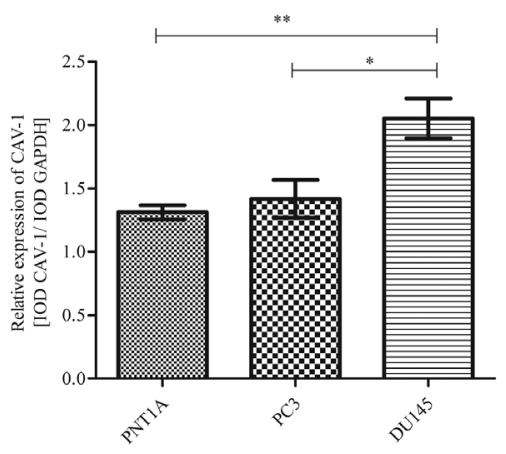

B
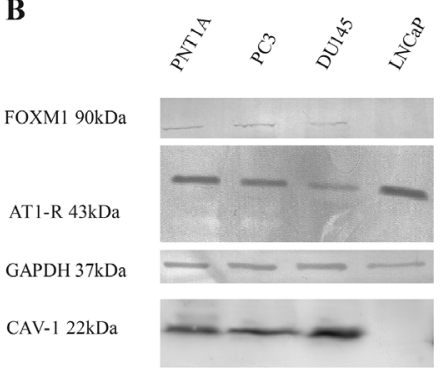

D

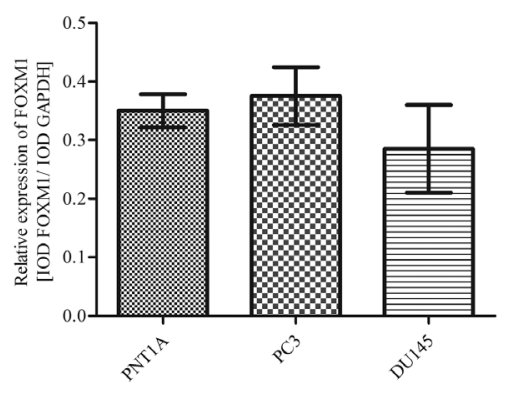

Figure 1. Expression of AT1-R, CAV-1 and FOXM1 in normal prostate and prostate cancer cell lines, as obtained by western blotting. (B) Representative images of western blot analysis. The relative expression of (A) AT1-R, (C) CAV-1 and (D) FOXM1 was determined by comparing their protein expression levels to those of GAPDH. ${ }^{*} P<0.05 ;{ }^{*} P<0.01$. The experiment was conducted in triplicate. AT1-R, angiotensin II type 1 receptor; CAV-1, caveolin-1; FOXM1, forkhead box M1; GAPDH, glyceraldehyde 3-phosphate dehydrogenase.

in the PC3 and PNT1A cells. High expression of CAV-1 was also observed in the DU145 cells.

Significant differences between the PNT1A and DU145 cells $(P<0.01)$, and between PC3 and DU145 cells $(P<0.05)$ were observed (Fig. 1C). FOXM1 protein expression was consistent with its mRNA expression pattern (Fig. 1D).

\section{CAV-1, FOXM1 and AT1-R expression in breast cancer cell lines}

In breast cell lines, a significant and positive correlation between the mRNA levels of FOXM1 and CAV-1 (rs $=0.4900 ; P=0.0500$ ) was observed, in addition to a tendency in correlation between the mRNA levels of FOXM1 and AT1-R (rs=0.5175; $P>0.05)$, and those of CAV-1 and AT1-R ( $r=0.3290 ; P>0.05)$. The mean expression levels of the investigated genes are presented in Table 4. However, in terms of invasiveness and metastatic potential, negative correlations were noticed. Thus, the normal cell line 184A1 exhibited the highest expression of CAV-1, FOXM1 and AT1-R (mean expression levels, 56.1, 9.4 and 44.0, respectively). The decrease of CAV-1 expression in the MDA-MB-231 and MCF-7 cells, compared with normal breast cells, was significant. The difference in expression of all the investigated genes between the two cancer cell lines was inversely correlated with their metastatic potential. Thus, the MDA-MB-231 cell line, which is characterised as having a low metastatic potential, exhibited a significantly higher expression of CAV-1 and FOXM1, in addition to 2 -fold increased expression of AT1-R, although this was not significant (Table 4).

At the protein level, AT1-R expression was the highest in the normal breast cell line 184A1, and lower in MDAMB-231 and MCF-7 cells. Significant differences in expression between 184A1 and MDA-MB-231 cells $(P<0.05)$, and between 184A1 and MCF-7 cells $(P<0.01)$ were observed (Fig. 2A). The apparent discrepancies observed

Table 4. Messenger RNA expression levels of AT1-R, CAV-1 and FOXM1 in normal breast and breast cancer cell lines.

Differences in expression were statistically analysed according to the metastatic potential of these cell lines, which was determined based on their well-documented properties.

\begin{tabular}{|c|c|c|c|c|c|c|c|c|}
\hline \multirow[b]{2}{*}{ Cell line } & \multirow[b]{2}{*}{$\begin{array}{l}\text { Metastasis } \\
\text { potential }\end{array}$} & \multicolumn{3}{|c|}{ Mean expression level } & \multirow{2}{*}{$\begin{array}{l}\text { Metastasis potential in normal breast } \\
\text { and breast cancer cell lines }\end{array}$} & \multicolumn{3}{|l|}{$P$-value } \\
\hline & & CAV-1 & AT1-R & FOXM1 & & CAV-1 & AT1-R & FOXM1 \\
\hline $184 \mathrm{~A} 1$ & 0 & 56.1 & 44 & 9.4 & 0 vs. low & 0.03 & ns & ns \\
\hline MDA-MB-231 & low & 24.7 & 45.5 & 17.2 & 0 vs. high & 0.002 & ns & 0.007 \\
\hline MCF-7 & high & 0.5 & 27.1 & 4.2 & low vs. high & 0.02 & ns & 0.03 \\
\hline
\end{tabular}

ns, not significant; CAV-1, caveolin-1; AT1-R, angiotensin II type 1 receptor; FOXM1, forkhead box M1 
$\mathbf{A}$

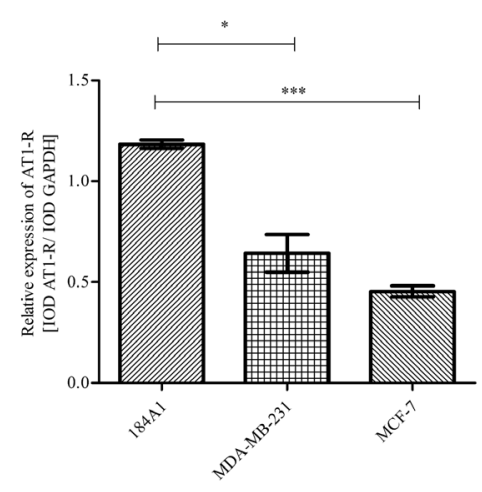

C

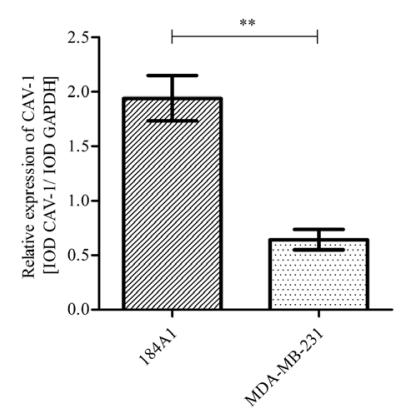

B

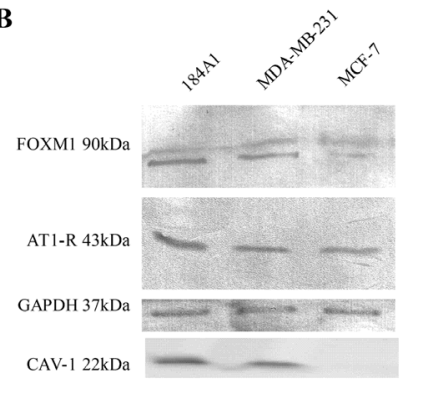

D

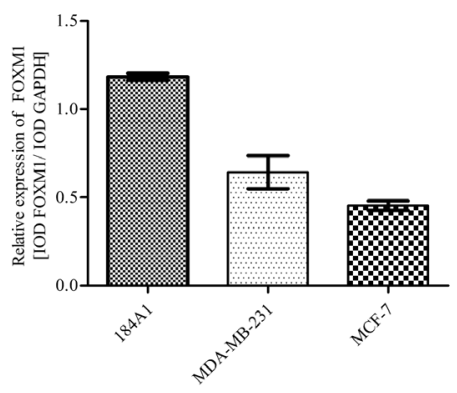

Figure 2. Expression of AT1-R, CAV-1 and FOXM1 in normal breast and breast cancer cell lines, as obtained by western blotting. (B) Representative images of western blot analysis. The relative expression of (A) AT1-R, (C) CAV-1 and (D) FOXM1 was determined by comparing their protein expression levels to those of GAPDH. ${ }^{*} P<0.05 ;{ }^{* *} P<0.01 ;{ }^{* * *} P<0.001$. The experiment was conducted in triplicate. AT1-R, angiotensin II type 1 receptor; CAV-1, caveolin-1; FOXM1, forkhead box M1; GAPDH, glyceraldehyde 3-phosphate dehydrogenase.

between the mRNA and protein expression patterns may be associated with post-transcriptional modifications in gene expression profiles. The pattern of CAV-1 protein expression was similar to its mRNA expression pattern, with no detectable expression in MCF-7 cells (Fig. 2C). The difference in CAV-1 expression between 184A 1 and MDA-MB-231 cells was significant $(P<0.01)$. The highest protein expression levels of FOXM1 were detected in the normal breast cell line 184A1, compared with decreased expression levels observed in MDA-MB-231 and the lowest level in the MCF-7 cells (Fig. 2D).

\section{DISCUSSION}

Since its identification, the function of CAV-1 in tumorigenesis has been disputable. It is well-documented that CAV-1 has a dual role in regulating cancerogenesis (Grande-Garcia \& Del Pozo, 2008; Senetta et al., 2013). It may act as a tumour suppressor in breast cancer, where it downregulates numerous oncogenes such as Src or Ras (Senetta et al., 2013). In contrast, tumour promoter properties of CAV-1 have been associated with the regulation of cyclin D1 expression and cell cycle progression via interaction with Stat3 oncoprotein, EGF signalling or as a transducer of cell signalling by Rho-guanosine triphosphatases (Grande-Garcia \& Del Pozo, 2008). Furthermore, as a part of caveolae, CAV-1 also participates in endocytosis and signal transduction in cells (Senetta et al., 2013). Interactions between CAV-1, MMP2 and MMP9 are key factors in cell motility and dynamics, which, simultaneously with VEGFinduced angiogenesis, may lead to tumour metastasis (Goetz et al., 2008; Han \& Zhu, 2010). The antimetastatic function of CAV-1 has been also reported for brain tumours, where CAV-1 suppressed the process of metastasis via inhibition of the Stat3 oncoprotein (Chiu et al., 2011). Thus, CAV-1 is considered to act as a tumour suppressor in the early stages of tumour development, whereas in more advanced stages it promotes tumorigenesis (Senetta et al., 2013). In prostate cancer, CAV-1 has been reported to be a potential highrisk marker (Gumulec et al., 2012). In the study presented here, an increase in the CAV-1 expression at the protein and mRNA levels was observed to be associated with the metastatic potential of the prostate cell lines. The DU145 cell line, which is derived from a metastatic central nervous system lesion, and is known to possess a higher metastatic potential than LNCaP or PC3 cells (Dominska et al., 2012), exhibited the highest expression levels of CAV-1 in this study. This observation may indicate that high CAV1 expression may be one of the factors contributing to the development of increased cell invasiveness. However, CAV-1 expression in the PC3 and LNCaP cancer cells was significantly lower than in normal PNT1A cells. This fact may indicate that CAV-1 is required for the correct functioning of normal prostate cells, but the oncogenic transformation of these cells may result in the enhancement of the tumour promoter properties of CAV-1. Contrary to the findings in the aforementioned prostate cell line, a negative correlation between CAV-1 expression and metastatic potential was observed for breast cell lines, with the exception of 184A1, the normal breast cell line tested in the present study, which exhibited the highest expression levels of CAV-1, both at the mRNA and protein levels, supporting the hypothesis that CAV-1 is required for the correct functioning of normal cells. 
In breast cancer, CAV-1 was reported to potentially increase angiogenesis and metastasis by activation of the protein kinase $\mathrm{C}$, MAPKs and phosphoinositide 3-kinase/Akt (Uemura et al., 2008b). Contrary to this assumption, western blotting and RT-qPCR results of the study presented here have demonstrated relatively high expression levels of CAV-1 in normal breast cells and the less aggressive MDA-MB-231 cancer cell line, which were higher than in the MCF-7 cancer cells, indicating that CAV-1 does not exert a tumorigenic role in breast cancer. These observations are consistent with the fact that CAV-1 has been reported to act as a tumour suppressor in breast cancer (Chiu et al., 2011).

In the study presented here, the expression of other genes assumed to co-participate in the development of the invasiveness potential of cancer cells and possibly participating in CAV-1 signalling, was also investigated. One of these candidate genes is Ang II, which has been suggested to participate in cancer metastasis and invasiveness (Dominska et al., 2012). Ang II increases the proliferation of breast cells and influences angiogenesis via AT1-R (Jethon et al., 2012). Ang II was also reported to modulate the migration of LNCaP cells (Dominska et al., 2012). Furthermore, AT1-R is known to modulate the viability of prostate cancer cells (Dominska et al., 2009), and its blockers may cause a beneficial effect on tumour progression and metastasis (Uemura et al., 2008b). Our study revealed here a positive correlation between CAV-1 and AT1-R expression, and observed a similar expression profile for CAV-1 and AT1-R in the two types of tumour cell lines evaluated. The highest expression levels of AT1-R were observed in the androgen-positive PC3 and DU145 cell lines, while the lowest expression levels of AT1-R were observed in androgen-negative LNCaP cells (Cariaga-Martinez et al., 2013). In the normal cell line PNT1A, the expression of AT1-R was $\sim 3$-fold lower than in the highly metastatic cell lines PC3 and DU145. The protein expression levels of AT1-R were the highest in the LNCaP cells when compared with PC3, PNT1A and DU145 cells, which displayed lower expression levels of AT1-R. The relatively high expression levels of AT1-R in the prostate cancer cell line LNCaP may not be associated with proliferation and migration. Kosaka and coworkers (2007) et al. observed that blockers of AT1-R did not alter the proliferation of $\mathrm{LNCaP}$ cells, indicating that AT1-R in this prostate cancer cell line is not associated with proliferation. In breast cancer, the expression pattern of AT1-R was similar to that of CAV-1, indicating that the expression of AT1-R decreases with increasing metastatic potential, although it should be considered whether the expression levels of AT1-R correlate with the response to Ang II in these cells.

The FOXM1 transcription factor appears to be associated with the AT1-R and CAV-1 genes, according to the results presented here. In the two types of cell lines investigated, a positive and significant correlation between FOXM1 and CAV-1 expression, and a strong coexpression tendency with AT1-R, was noticed. The expression pattern of FOXM1 according to metastatic potential is consistent with that observed for AT1-R and CAV-1, with a significant increase in expression in prostate cancer cell lines in relation to metastasis, and a decrease in expression in breast cancer cell lines in relation to metastasis, while normal breast and prostate cell lines exhibited relatively high FOXM1 expression. FOXM1 was demonstrated to be involved in the regulation of cellular processes characteristic of cancer (Halasi and Gartel, 2013). In addition, numerous correlations between FOXM1 and cancer-associated genes have been identified (Xu et al., 2015), including direct coregulation between FOXM1 and CAV-1 (Huang et al., 2012).
Huang et al (Huang et al., 2012) reported that the expression levels of CAV-1 directly correlate with those of FOXM1 in pancreatic cancer cell lines and tumour samples. Notably, this correlation is direct and positive, indicating that overexpression of FOXM1 leads to upregulation of CAV-1, while knockdown of FOXM1 produces the opposite effect (Huang et al., 2012). The results of the study presented here confirm the existence of this FOXM1-CAV-1 signalling pathway in the two types of cell lines investigated, in spite of the correlation with metastatic properties being adverse. This discrepancy may be due to the dual functional properties of CAV-1, but the present results confirm the close functional connection that exists between the FOXM1 and CAV-1 genes. Furthermore, the strong tendency in association of FOXM1 and AT1-R expression, shown here for the first time, suggests that AT1-R may be another target gene for FOXM1, and may possibly be a third player in the FOXM1-CAV-1 axis, thus influencing the functioning of these genes. However, this assumption must be further investigated to determine if the correlation is direct or indirect.

The study presented here also revealed that all the investigated genes (CAV-1, FOXM1 and AT1-R) exhibited comparable high expression levels in normal prostate and breast cell lines. This may indicate that all of these genes are required for proper cell functioning, and during the initiation of cancerogenesis they are timely inactivated, thus enabling the cell to be redirected to the cancer progression pathway. However, these observations may be also due to cell line specificity, as a result of the immortalization method employed to establish the different cell lines.

In conclusion, the results presented here indicate that CAV-1, FOXM1 and AT1-R are potential markers of tumorigenesis, depending on the type of cancer and its characteristics in vitro. The relative expression pattern of these genes appears to influence the metastatic potential of the cells. However, the complexity of their molecular functions appears to influence these features. CAV-1, FOXM1 and AT1-R exhibit similar, although contradictory expression pattern in breast and prostate cancer cell lines, and AT1-R seems to be part of the CAV-1 and FOXM1 signalling pathway, although the association between FOXM1 and AT1-R must be further investigated.

\section{Acknowledgements}

This work was supported by the Medical University of Lodz Contract Grant: 503/0-078-04/503-01.

\section{REFERENCES}

Agelaki S, Spiliotaki M, Markomanolaki H, Kallergi G, Mavroudis D, Georgoulias V, Stournaras C (2009) Caveolin-1 regulates EGFR signaling in MCF-7 breast cancer cells and enhances gefitinib-induced tumor cell inhibition. Cancer Biol Ther 8: 1470-1477.

Bartholomew JN, Volonte D, Galbiati F (2009) Caveolin-1 regulates the antagonistic pleiotropic properties of cellular senescence through a novel Mdm2/p53-mediated pathway. Cancer Res 69: 2878-2886. http://dx.doi.org/10.1158/0008-5472.CAN-08-2857.

Bergamaschi A, Madak-Erdogan Z, Kim YJ, Choi YL, Lu H, Katzenellenbogen BS (2014) The forkhead transcription factor FOXM1 promotes endocrine resistance and invasiveness in estrogen receptorpositive breast cancer by expansion of stem-like cancer cells. Breast Cancer Res 16: 436. http://dx.doi.org/10.1186/s13058-014-0436-4.

Bouras T, Lisanti MP, Pestell RG (2004) Caveolin-1 in breast cancer. Cancer Biol Ther 3: 931-941.

Burgermeister E, Liscovitch M, Rocken C, Schmid RM, Ebert MP (2008) Caveats of caveolin-1 in cancer progression. Cancer Lett 268: 187-201. http://dx.doi.org/10.1016/j.canlet.2008.03.055.

Cariaga-Martinez AE, Lopez-Ruiz P, Nombela-Blanco MP, Motino O, Gonzalez-Corp, Rodriguez-Ubreva J, Lobo MV, Cortes MA, Colas B (2013) Distinct and specific roles of AKT1 and AKT2 in androgen-sensitive and androgen-independent prostate cancer 
cells. Cell Signal 25: 1586-1597. http://dx.doi.org/10.1016/j.cellsig.2013.03.019.

Chandran UR, Ma C, Dhir R, Bisceglia M, Lyons-Weiler M, Liang W, Michalopoulos G, Becich M, and Monzon FA (2007) Gene expression profiles of prostate cancer reveal involvement of multiple molecular pathways in the metastatic process. BMC Cancer 7: 64 . http://dx.doi.org/10.1186/1471-2407-7-64.

Chiu WT, Lee HT, Huang FJ, Aldape KD, Yao J, Steeg PS, Chou CY, Lu Z, Xie K, Huang S (2011) Caveolin-1 upregulation mediates suppression of primary breast tumor growth and brain metastases by stat3 inhibition. Cancer Res 71: 4932-4943. http://dx.doi. org/10.1158/0008-5472.CAN-10-4249.

Dai B, Kang SH, Gong W, Liu M, Aldape KD, Sawaya R, Huang S (2007) Aberrant FoxM1B expression increases matrix metalloproteinase- 2 transcription and enhances the invasion of glioma cells. Oncogene 26: 6212-6219. http://dx.doi.org/10.1038/sj.onc.1210443.

Dominska K, Lachowicz-Ochedalska A (2008) The involvement of the renin-angiotensin system (RAS) in cancerogenesis. Postepy Biochem 54: 294-300.

Dominska K, Piastowska AW, Rebas E, Lachowicz-Ochedalska A (2009) The influence of peptides from the angiotensin family on tyrosine kinase activity and cell viability in a human hormone-dependent prostate cancer line. Endokrynol Pol 60: 363-369.

Dominska K, Piastowska-Ciesielska AW, Lachowicz-Ochedalska A, Ochedalski T (2012) Similarities and differences between effects of angiotensin III and angiotensin II on human prostate cancer cell migration and proliferation. Peptides 37: 200-206. http://dx.doi. org/10.1016/j.peptides.2012.07.022

Glait C, Ravid D, Lee SW, Liscovitch M, Werner H (2006) Caveolin-1 controls BRCA1 gene expression and cellular localization in human breast cancer cells. FEBS Lett 580: 5268-5274. http://dx.doi. org/10.1016/j.febslet.2006.08.071.

Goetz JG, Lajoie P, Wiseman SM, Nabi IR (2008) Caveolin-1 in tumor progression: the good, the bad and the ugly. Cancer Metastasis Rev 27: 715-735. http:/ /dx.doi.org/10.1007/s10555-008-9160-9.

Grande-Garcia A, Del Pozo MA (2008) Caveolin-1 in cell polarization and directional migration. Eur J Cell Biol 87: 641-647. http://dx.doi. org/10.1016/j.ejcb.2008.02.001.

Gumulec J, Sochor J, Hlavna M, Sztalmachova M, Krizkova S, Babula P, Hrabec R, Rovny A, Adam V, Eckschlager T, Kizek R, Masarik M (2012) Caveolin-1 as a potential high-risk prostate cancer biomarker. Oncol Rep 27: 831-841. http://dx.doi.org/10.3892/ or.2011.1587.

Halasi M, Gartel AL (2013) FOX(M1) news--it is cancer. Mol Cancer Ther 12: 245-254. http://dx.doi.org/10.1158/1535-7163.MCT-120712.

Han F, Zhu HG (2010) Caveolin-1 regulating the invasion and expression of matrix metalloproteinase (MMPs) in pancreatic carcinoma cells. J Surg Res 159: 443-450. http://dx.doi.org/10.1016/j. jss.2009.03.079.

Huang C, Qiu Z, Wang L, Peng Z, Jia Z, Logsdon CD, Le X, Wei D, Huang S, Xie K (2012) A novel FoxM1-caveolin signaling pathway promotes pancreatic cancer invasion and metastasis. Cancer Res 72 655-665. http://dx.doi.org/10.1158/0008-5472.CAN-11-3102.

Jethon A, Pula B, Piotrowska A, Wojnar A, Rys J, Dziegiel P, Podhorska-Okolow M (2012) Angiotensin II type 1 receptor (AT-1R) expression correlates with VEGF-A and VEGF-D expression in invasive ductal breast cancer. Pathol Oncol Res 18: 867-873. http:// dx.doi.org/10.1007/s12253-012-9516-x.

Kalin TV, Ustiyan V, Kalinichenko VV (2011) Multiple faces of FoxM1 transcription factor: lessons from transgenic mouse models. Cell Cycle 10: 396-405.

Kalin TV, Wang IC, Ackerson TJ, Major ML, Detrisac CJ, Kalinichenko VV, Lyubimov A, Costa RH (2006) Increased levels of the FoxM1 transcription factor accelerate development and progression of prostate carcinomas in both TRAMP and LADY transgenic mice. Cancer Res 66: 1712-1720. http://dx.doi.org/10.1158/00085472.CAN-05-3138.

Kim IM, Ackerson T, Ramakrishna S, Tretiakova M, Wang IC, Kalin TV, Major ML, Gusarova GA, Yoder HM, Costa RH, Kalinichenko VV (2006) The Forkhead Box $\mathrm{m} 1$ transcription factor stimulates the proliferation of tumor cells during development of lung cancer. Cancer Res 66: 2153-2161. http://dx.doi.org/10.1158/0008-5472. CAN-05-3003.

Kosaka T, Miyajima A, Takayama E, Kikuchi E, Nakashima J, Ohigashi T, Asano T, Sakamoto M, Okita H, Murai M, Hayakawa M (2007) Angiotensin II type 1 receptor antagonist as an angiogenic inhibitor in prostate cancer. Prostate 67: 41-49. http://dx.doi. org/10.1002/pros.20486.

Laoukili J, Stahl M, Medema RH (2007) FoxM1: at the crossroads of ageing and cancer. Biochim Biophys Acta 1775: 92-102. http://dx.doi. org/10.1016/j.bbcan.2006.08.006

Liu M, Dai B, Kang SH, Ban K, Huang FJ, Lang FF, Aldape KD, Xie TX, Pelloski CE, Xie K, Sawaya R, Huang S (2006) FoxM1B is overexpressed in human glioblastomas and critically regulates the tumorigenicity of glioma cells. Cancer Res 66: 3593-3602. http:// dx.doi.org/10.1158/0008-5472.CAN-05-2912.

Mahmoud AM, Al-Alem U, Ali MM, Bosland MC (2015) Genistein increases estrogen receptor beta expression in prostate cancer via reducing its promoter methylation. I Steroid Biochem Mol Biol 152: 62-75. http://dx.doi.org/10.1016/j.jsbmb.2015.04.018.

Millour J, Constantinidou D, Stavropoulou AV, Wilson MS, Myatt SS, Kwok JM, Sivanandan K, Coombes RC, Medema RH, Hartman J, Lykkesfeldt AE, Lam EW (2010) FOXM1 is a transcriptional target of ERalpha and has a critical role in breast cancer endocrine sensitivity and resistance. Oncogene 29: 2983-2995. http://dx.doi. org/10.1038/onc. 2010.47

Park HJ, Gusarova G, Wang Z, Carr JR, Li J, Kim KH, Qiu J, Park YD, Williamson PR, Hay N, Tyner AL, Lau LF, Costa RH, Raychaudhuri P (2011) Deregulation of FoxM1b leads to tumour metastasis. EMBO Mol Med 3: 21-34. http://dx.doi.org/10.1002/ emmm.201000107.

Pfaffl MW, Horgan GW, Dempfle L (2002) Relative expression software tool (REST) for group-wise comparison and statistical analysis of relative expression results in real-time PCR. Nucleic Acids Res 30: e36.

Piastowska-Ciesielska AW, Dominska K, Nowakowska M, Gajewska M, Gajos-Michniewicz A, Ochedalski T (2014) Angiotensin modulates human mammary epithelial cell motility. I Renin.Angiotensin Aldosterone Syst 15: 419-429. http://dx.doi.org/10.1177/1470320313475904.

Piastowska-Ciesielska AW, Drobnik J, Zarzynska J, Dominska K, Russell JA, Ochedalski T (2011) Influence of myocardial infarction on changes in the expression of angiotensin type 1 receptor in the rat prostate. Folia Histochem Cytobiol 49: 497-503.

Piastowska-Ciesielska AW, Kozlowski M, Wagner W, Dominska K, Ochedalski T (2013a) Effect of an angiotensin II type 1 receptor blocker on caveolin-1 expression in prostate cancer cells. Arch Med Sci 9: 739-744. http://dx.doi.org/10.5114/aoms.2012.30955.

Piastowska-Ciesielska AW, Pluciennik E, Wojcik-Krowiranda K, Bienkiewicz A, Nowakowska M, Pospiech K, Bednarek AK, Dominska K, Ochedalski T (2013b) Correlation between VEGFR-2 receptor kinase domain-containing receptor (KDR) mRNA and angiotensin II receptor type 1 (AT1-R) mRNA in endometrial cancer. Cytokine 61: 639-644. http://dx.doi.org/10.1016/j.cyto.2012.11.017.

Senetta R, Stella G, Pozzi E, Sturli N, Massi D, Cassoni P (2013) Caveolin-1 as a promoter of tumour spreading: when, how, where and why. I Cell Mol Med 17: 325-336. http://dx.doi.org/10.1111/ jcmm.12030.

Siegel RL, Miller KD, Jemal A (2015) Cancer statistics, 2015. CA Cancer J Clin 65: 5-29. http://dx.doi.org/10.3322/caac.21254.

Trimmer C Sotgia F, Whitaker-Menezes D, Balliet RM, Eaton G, Martinez-Outschoorn UE, Pavlides S, Howell A, Iozzo RV, Pestell RG, Scherer PE, Capozza F, Lisanti MP (2011) Caveolin-1 and mitochondrial SOD2 (MnSOD) function as tumor suppressors in the stromal microenvironment: a new genetically tractable model for human cancer associated fibroblasts. Cancer Biol Ther 11: 383-394.

Uemura H, Ishiguro H, Ishiguro Y, Hoshino K, Takahashi S, Kubota Y (2008a) Angiotensin II induces oxidative stress in prostate cancer. Mol Cancer Res 6: 250-258. http://dx.doi.org/10.1158/1541-7786. MCR-07-0289.

Uemura H, Ishiguro H, Kubota Y (2008b) Pharmacology and new perspectives of angiotensin II receptor blocker in prostate cancer treatment. Int J Urol 15: 19-26. http://dx.doi.org/10.1111/j.14422042.2007.01937.x

Uemura H, Ishiguro H, Nagashima Y, Sasaki T, Nakaigawa N, Hasumi H, Kato S, Kubota Y (2005a) Antiproliferative activity of angiotensin II receptor blocker through cross-talk between stromal and epithelial prostate cancer cells. Mol Cancer Ther 4: 1699-1709. http:// dx.doi.org/10.1158/1535-7163.MCT-04-0295.

Uemura H, Nakaigawa N, Ishiguro H, Kubota Y (2005b) Antiproliferative efficacy of angiotensin II receptor blockers in prostate cancer. Curr Cancer Drug Targets 5: 307-323.

Wang IC, Chen YJ, Hughes DE, Ackerson T, Major ML, Kalinichenko VV, Costa RH, Raychaudhuri P, Tyner AL, Lau LF (2008) FoxM1 regulates transcription of JNK1 to promote the G1/S transition and tumor cell invasiveness. J Biol Chem 283: 20770-20778. http://dx. doi.org/10.1074/jbc.M709892200.

Xu XS, Miao RC, Wan Y, Zhang LQ, Qu K, Liu C (2015) FoxM1 as a novel therapeutic target for cancer drug therapy. Asian Pac J Cancer Prev 16: 23-29.

Yang G, Goltsov AA, Ren C, Kurosaka S, Edamura K, Logothetis R, DeMayo FJ, Troncoso P, Blando J, DiGiovanni J, Thompson TC (2012) Caveolin-1 upregulation contributes to c-Myc-induced highgrade prostatic intraepithelial neoplasia and prostate cancer. Mol Cancer Res 10: 218-229. http://dx.doi.org/10.1158/1541-7786.MCR$11-0451$.

Zhang Y, Zhang N, Dai B, Liu M, Sawaya R, Xie K, Huang S (2008) FoxM1B transcriptionally regulates vascular endothelial growth factor expression and promotes the angiogenesis and growth of glioma cells. Cancer Res 68: 8733-8742. http://dx.doi.org/10.1158/00085472.CAN-08-1968. 